(RESEARCH ARTICLE)

\title{
Risk indicators of apical periodontitis in an adult Sudanese population
}

\author{
Israa Abdulrhman Ahmed 1,2, Raouf Wahab Ali 2 and Amal Mohamed Mudawi 1,3* \\ ${ }^{1}$ Department of Restorative Dentistry, Faculty of Dentistry, University of Khartoum, Sudan. \\ 2 Department of Operative Dentistry, Dental College, University of Science and Technology, Sudan. \\ ${ }^{3}$ Department of Preventive and Community Dentistry, Faculty of Dentistry, University of Khartoum, Sudan.
}

Publication history: Received on 09 August 2020; revised on 20 September 2020; accepted on 22 September 2020

Article DOI: https://doi.org/10.30574/wjarr.2020.7.3.0295

\begin{abstract}
Endodontic and periapical status are significant restraints that can predict tooth existence and the potential necessity for dental treatment in the growing dental population. The aim of this study is to estimate risk indicators for apical periodontitis (AP) in an adult Sudanese patients. This is an observational cross-sectional hospital-based study. Clinical and radiographical examination of 200 patients above18 years seeking routine dental management for the first time at the dental clinics (University of Khartoum) and the Dental Hospital (University of Science and Technology) was performed. The clinical examination included history and intra oral examination of coronal and periodontal status of each individual tooth. Data were assessed using the chi-square test and odds ratio at significant level of 5\% and confidence level of 95\%. Radiographs revealed that 624 teeth (48.7\% in the maxilla; $51.3 \%$ in the mandible) were lost leaving a total of 4967 teeth to be examined. AP was found in 95 patients (47\%) and 3.3\% of the teeth. A remarkably increased risk for AP was detected in teeth with root fillings, specifically technical inadequate ones $(\mathrm{OR}=4.30, \mathrm{P}<0.05)$. Presence of remaining root, coronal restoration, inadequate restoration and lost restoration also increased the risk for AP $(\mathrm{P}<0.001)$. Teeth with mobility and probing pocket depth of more than $4 \mathrm{~mm}$ were also associated with AP. Therefore, the main risk indicators of AP were the high plaque percentage, radiographic evidence of root fillings, the incidence of numerous carious lesions and the inappropriateness of dental treatment.
\end{abstract}

Keywords: Risk-Indicators; Apical Periodontitis; Adult Population; Root filled teeth

\section{Introduction}

AP is an acute or chronic inflammatory process around the apex of a tooth root; it results from microbial infection of the teeth root canals. It is a wide spread disease with an obvious cumulative economic impact, especially when we consider the cost and training need for its only viable treatment which is root canal treatment or retreatment [1-7]. Diagnosis of AP necessitates evaluation of the patient's symptoms and signs. However, the majority of AP cases are asymptomatic, so the diagnosis is based mainly on the radiographic examination [8].

A parameter is described as a 'risk indicator' when its occurrence increases the individual's risk of demonstrating the disease. Risk indicators might be directly linked with the disease [9]. Identification of individual risk indicator could help in selection of patients/ or teeth for extra radiographic examination. Numerous prior studies have tried to detect risk indicators of AP. It has been concluded that the presence and adequacy of the root canal filling, $[1,10,11,12,13]$ the quality of the coronal restoration, $[14,15]$ decayed and filled teeth, $[1,3,16]$ were related with the presence of AP [15]. Results from western populations have revealed that age, smoking, presence of diabetes mellitus type II, and the frequency of dental visits, were associated with the existence of AP as well $[17,18,10,19,9,20,21]$. The objective of this study is to identify some risk indicators for AP in an adult Sudanese population in Khartoum State. This may be a valuable estimate in the development of under and postgraduate dental education.

\footnotetext{
${ }^{*}$ Corresponding author: Amal Mohamed Mudawi, Associate Professor, Faculty of Dentistry, University of Khartoum, Sudan.

E-mail: amudawi63@hotmail.com 


\section{Material and methods}

\subsection{Study Population}

The sample included 200 adult patients seeking routine dental care and attending the dental clinics at the Faculty of Dentistry (University of Khartoum) and the Dental Hospital at the (University of Science and Technology).

The inclusion criteria in the study were that only patients attending for the first time were involved. Patients under 18 years, pregnant ladies and patients with less than 7 remaining teeth were not included.

\subsection{Ethical Approval}

The research protocol was approved by the ethical committee of the dental faculty; University of Khartoum. All participants signed a written informed consent.

\subsection{Clinical Examination}

All patients were clinically and radiographically examined. For each patient, a history and examination form has been filled recording the following information: - age, gender, oral hygiene practice, Diabetes mellitus history, sum of remaining teeth (not including third molars), smoking history and frequency of dental visits. Plaque accumulation percentage was also estimated by dividing the sum of plaque containing surfaces by the total number of available surfaces. For each tooth, the following data has been collected:

\subsubsection{The coronal status}

- $\quad$ Decayed Tooth (Primary or Secondary Carious Lesions).

- Tooth with Intra or Extra Coronal Restoration.

- Tooth with Inadequate or Lost Restoration.

\subsubsection{The Periodontal status}

- Bleeding on Probing percentage: was estimated by dividing the sum of gingival bleeding surfaces by the entire number of available surfaces.

- Probing Pocket Depth in mm: The pocket was estimated at 6 points on each tooth (mesio-buccal, mid-buccal, disto-buccal, and the equivalent lingual sites).

- Gingival recession was also measured as the distance of the free gingival margin to the cemento-enamel junction.

- Attachment Loss in mm: Clinical attachment loss is the distance from the cemento- enamel junction to the apical extent of the pocket.

- Tooth Mobility: Mobility was estimated by moving the teeth in a bucco-lingual and occluso-apical direction. Minor mobility, beyond that which is physiological, was graded as I. If the mobility is slightly more but the tooth cannot be depressed apically in the alveolus, it was recorded as II. If the mobility is advanced to the degree that the tooth may be depressed apically, it was scored as III.

- Furcation involvement: The extension of pockets into furcations was graded according to the following classification: Degree I; incipient or early supra bony pocket extension into the furcation area with slight loss of bone Degree II; extension of the pocket into the furcation leaving a portion of the alveolar bone and periodontal ligament intact allowing only partial penetration of the probe into the furcation area; Degree III; through and through extension of the pocket into the furcation area. All teeth have been recorded according to FDI nomenclature.

\subsection{Radiographic Examination}

A combination of panoramic and peri-apical radiographs was taken by a dental experienced radiologist, using Cranex 3+ Ceph (Sore dex orion corporation, Finland) X ray unit and Kodak (MXG and Dental Intra oral E- speed) films (Estman Kodak Company, Rochester New York USA). The prei-apical radiograph has been taken when the tooth apical area was not clear on the panoramic view. The paralleling technique was used for taking the peri-apical radiographs (using Endo Ray II film holder, Dentsply Rinn Corporation USA). An experienced dental assistant processed the films manually. 


\subsection{Radiographic Evaluation}

From the radiographic examination, all teeth excluding third molars were graded according to the FDI nomenclature. Teeth have been categorized as;

- Normal: No periapical radiolucency and normal width of periodontal ligament space.

- Endodontically treated: A tooth with a radio-opaque material in the root canal.

- Apical Periodontitis: A tooth with distinct periapical radiolucency or widening of the periodontal ligament space exceeding two times the normal width.

- Multi-rooted teeth were classified according to the root displaying the most severe periapical radiolucency.

The following information were recorded in a structured form for each patient

- Number and location of teeth without root filling having identifiable AP.

- Number and location of teeth with root filling having identifiable AP.

- Number and location of RF teeth.

- Satisfactory length extension of root filling: filling material present in the root canal within 0-2 mm of the radiographic apex.

- Unsatisfactory length extension of root filling: filling material present in the root canal more than $2 \mathrm{~mm}$ from the radiographic apex (shorter or extruded beyond the apex).

\subsection{The main investigator}

The radiographs were examined by one observer (Ahmed, I.) assisted by an experienced radiologist, under standardized situations using consistently illuminated viewing box.

\subsection{The intra-observer reproducibility}

This was evaluated by a double scoring of randomly selected 50 patients. The intra-observer agreement test estimated a Cohen's Kappa value of 0.951 .

\subsection{Data analysis}

The Statistical Package for social Sciences (SPSS) version 15 was used for data management. The data was then transferred to the software of the Epidemiologic Perspectives and Innovation programme (PEPI-for-Windows).

Data was analysed using the chi-square test and odds ratio. P- value less than 0.05 was considered as significant.

\section{Results}

Age of the 200 participants varied from 18 to 75 years with a mean \pm SD age of $34.0 \pm 12.9$ years. Most of the study population were females (76.5\%). Not including the third molar teeth, $624(12.5 \%)$ teeth were lost (48.7\% in the maxilla; $51.3 \%$ in the mandible). The number of missing teeth ranged from 1-16 per patient, with an average of 12 teeth per patient.

\subsection{Periapical Status}

The periapical status of 4976 teeth was estimated, with a range of $12-28$ teeth per patient. Ninety-five (47.5\%) patients had AP in one or more tooth (range 1-7). A total of 163 (3.3\%) teeth had AP.

\subsection{Coronal Status}

Of the 4976 teeth included in the study, 3951 (79.4\%) teeth were intact, 255 (5.1\%) teeth had a restoration and 595 (11.6\%) carious teeth (Table 1). Sixty five percent of the decayed teeth had AP while AP has been found in $0.32 \%$ of sound teeth.

\subsection{Periodontal Status}

The plaque accumulation was more than $20 \%$ in $95(47.5 \%)$ patients (Figure 1). There was no bleeding on probing in $133(66.5 \%)$ patients, less than $20 \%$ bleeding in $58(29.0 \%)$ patients and more than $20 \%$ in $9(4.5 \%)$ patients. There were $4912(98.7 \%)$ teeth with normal mobility and $64(1.3 \%)$ teeth with mobility. The probing pocket depth was $\leq 3$ 
$\mathrm{mm}$ in 981 (81.75\%) teeth and from 4-6 mm in 202 (16.8\%) teeth. There was no attachment loss in 1063 (88.6\%) teeth and from 1-4 mm loss in $78(6.5 \%)$ teeth. About 6 percent of molar teeth have furcation involvement.

Table 1 Number and percentage of teeth with AP according to coronal status.

\begin{tabular}{|l|l|l|l|}
\hline & Apical periodontitis (\%) & Normal (\%) & Total (\%) \\
\hline Intra-coronal restoration & $8(4.9)$ & $186(3.9)$ & $194(3.9)$ \\
\hline Extra-coronal restoration & $7(4.3)$ & $54(1.1)$ & $61(1.2)$ \\
\hline Lost restorations & $12(7.4)$ & $15(0.3)$ & $27(0.5)$ \\
\hline Inadequate restoration & $18(11.0)$ & $62(1.3)$ & $80(1.6)$ \\
\hline Decayed root & $44(27)$ & $24(0.5)$ & $68(1.4)$ \\
\hline Caries & $65(39.9)$ & $530(11.0)$ & $595(11.6)$ \\
\hline Intact & $9(5.5)$ & $3942(81.9)$ & $3951(79.4)$ \\
\hline Total & $163(3.3)$ & $4813(96.7)$ & $4976(100)$ \\
\hline
\end{tabular}

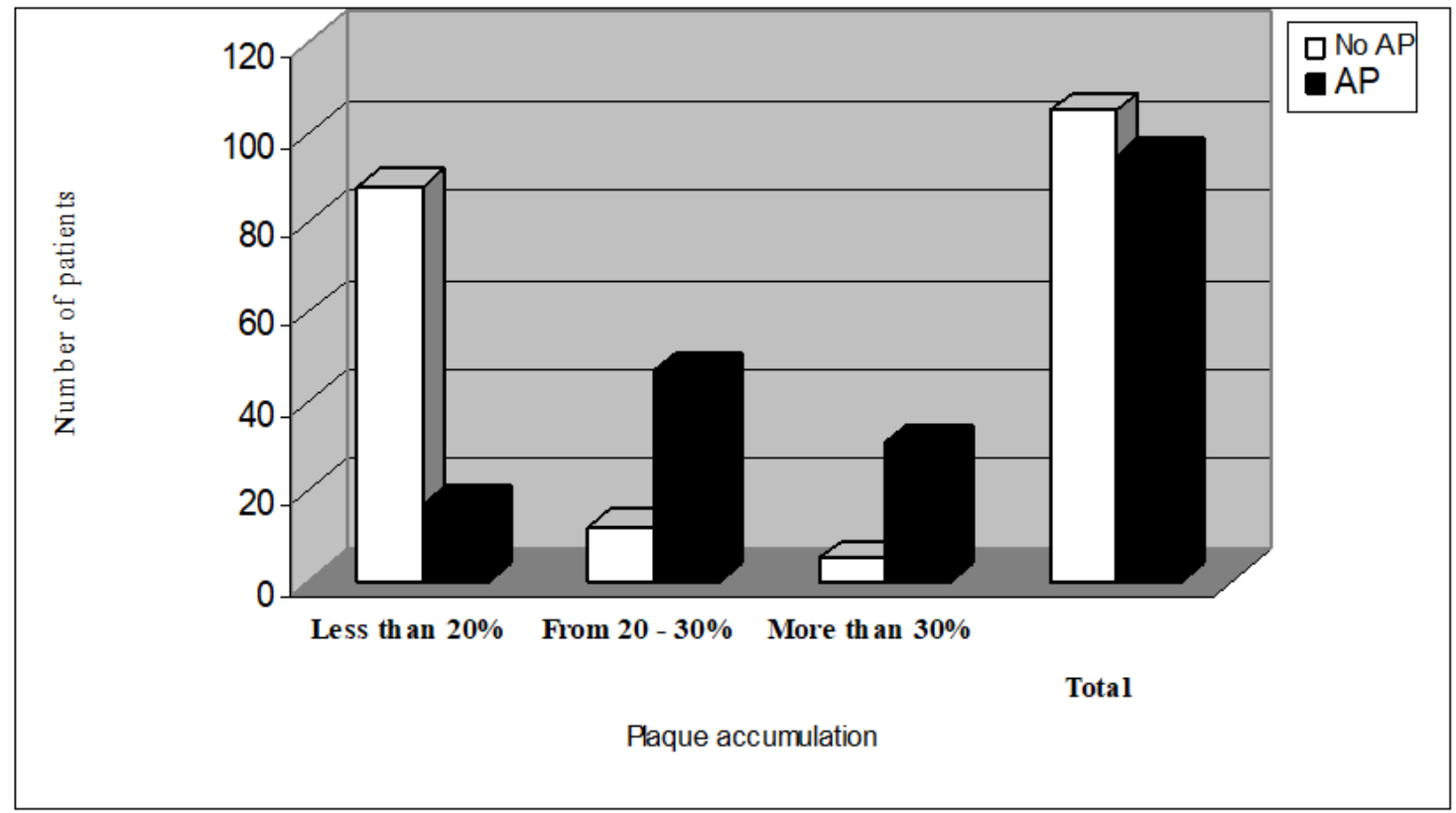

Figure 1 Distribution of the patients according to the plaque accumulation percentage

\subsection{Endodontic Treatment}

Seventy nine percent of the patients had no root fillings, while $21 \%$ had $\geq 1$ root filled teeth (range 1-6). Of the patients with root fillings, 25 (59.5\%) had AP, whereas 70 (44.3\%) of the patients without root fillings had AP. A total of 80 $(1.6 \%)$ teeth had been root filled. Of these root-filled teeth 26 (32.5\%) teeth had AP.

\subsection{Risk Indicators of AP}

The main aim of the statistical analyses was to identify the best predictive factors for having AP in patients and teeth. Tables 2 and 3 show the odds ratio (OR) with 95\% confidence interval (CI) and P- value for estimation of the statistical association between the possible risk indicators and the outcome variable (AP/ no AP).

Risk Indicators of AP / patients: The prevalence of teeth with AP increased with age (Table 2). The first three age groups (18- 47 years old) had a prevalence of teeth with AP between 2 and $4 \%$, though, the prevalence in the older groups ( $\geq 48$ years old) was higher $(6 \%)(\mathrm{OR}=2.46, \mathrm{P}>0.001)$. The probability of AP in males was twice that in females 
$(\mathrm{OR}=2.35, \mathrm{P}<0.05)$. An exceedingly increased risk for AP was detected in patients with plaque accumulation of more than $20 \%(\mathrm{OR}=19.22-28.96, \mathrm{P}<0.001)$. Ninety seven percent of the patients used tooth brush as an oral hygiene tool, while $3 \%$ used siwak. Among the study patients, 6 patients (3\%) were diabetic and 8 patients (4\%) were smokers. Most of the patients $(98.5 \%)$ were irregularly visiting the dentist. Patients with more than 4 missing teeth were significantly associated with having AP $(\mathrm{OR}=2.36, \mathrm{P}<0.05)$ (Table 2).

Risk Indicators of AP / teeth. An extremely increased risk for AP was seen in teeth with coronal restoration, inadequate restoration, lost restoration and remaining roots $(\mathrm{P}<0.001)$. A statistically significant difference was found between AP and teeth with mobility ( $\mathrm{P}<0.001$ ) (Table 3). Presence of probing pocket depth of more than $7 \mathrm{~mm}$ also increased the risk for AP $(\mathrm{P}<0.05)$ (Table 3). Inadequate root canal fillings were found in seventeen $(65.38 \%)$ of rootfilled teeth with apical periodontitis. Most of them being short of the radiographic apex. There was a statistically significant relationship between the adequacy of root fillings and the existence of AP (P<0.05). The probability of AP in teeth with unsatisfactory root fillings length was four times that in teeth with satisfactory root fillings $(\mathrm{OR}=4.30)$.

Table 2 Risk indicators of AP for patients

\begin{tabular}{|c|c|c|c|c|}
\hline Variables & Category & Adjusted OR & $95 \% \mathrm{CI}$ & P-value \\
\hline \multirow[t]{5}{*}{ Age } & $18-27(n=73)$ & 1.00 & - & - \\
\hline & $28-37(n=55)$ & 0.83 & $0.37-1.85$ & 0.755 \\
\hline & $38-47(n=38)$ & 2.56 & $1.08-6.35$ & 0.030 \\
\hline & $48-57(n=21)$ & 6.58 & $1.99-28.67$ & 0.001 \\
\hline & $58+(n=13)$ & 5.07 & $1.27-28.18$ & 0.018 \\
\hline \multirow[t]{2}{*}{ Gender } & Female $(\mathrm{n}=153)$ & 1.00 & - & - \\
\hline & Male $(n=47)$ & 2.35 & $1.16-4.97$ & 0.017 \\
\hline \multirow[t]{2}{*}{ Smoking } & No $(n=192)$ & 1.00 & - & - \\
\hline & Yes $(n=8)$ & 1.78 & $0.38-10.30$ & 0.613 \\
\hline \multirow[t]{2}{*}{ History of diabetes mellitus } & No $(n=194)$ & 1.00 & - & \\
\hline & Yes $(n=6)$ & 4.27 & $0.64-134.47$ & 0.167 \\
\hline \multirow[t]{3}{*}{ Oral hygiene practice (frequency) } & $1 /$ day $(\mathrm{n}=97)$ & 1.00 & - & - \\
\hline & 2/day $(n=79)$ & 0.64 & $0.34-1.22$ & 0.191 \\
\hline & More than 2/day $(n=24)$ & 1.10 & $0.42-2.98$ & 0.998 \\
\hline \multirow[t]{2}{*}{ Oral hygiene practice (tool) } & Tooth brush $(n=194)$ & 1.00 & - & - \\
\hline & Siwak $(n=6)$ & 4.23 & $0.64-133.20$ & 0.171 \\
\hline \multirow[t]{3}{*}{ Plaque accumulation \% } & Less than $20 \%(\mathrm{n}=105)$ & 1.00 & - & - \\
\hline & From $20-30 \%(n=59)$ & 19.22 & $8.34-50.52$ & $<0.001$ \\
\hline & More than $30 \%(n=36)$ & 28.96 & $9.97-110.76$ & $<0.001$ \\
\hline \multirow[t]{3}{*}{ Bleeding on Probing \% } & No bleeding $(\mathrm{n}=133)$ & 1.00 & - & - \\
\hline & From $1-20 \%(n=58)$ & 0.59 & $0.30-1.15$ & 0.128 \\
\hline & More than $20 \%(n=9)$ & 1.17 & $0.26-5.59$ & 1.00 \\
\hline \multirow[t]{3}{*}{ Number of missing teeth } & $0(\mathrm{n}=61)$ & 1.00 & - & \\
\hline & $1-3(n=68)$ & 1.30 & $0.61-2.81$ & 0.576 \\
\hline & $4+(n=71)$ & 2.36 & $1.12-5.14$ & 0.022 \\
\hline
\end{tabular}


Table 3 Risk indicators of AP for teeth

\begin{tabular}{|c|c|c|c|c|}
\hline Variables & Category & Adjusted OR & $95 \% \mathrm{CI}$ & P-value \\
\hline \multirow[t]{3}{*}{ Mobility } & Normal $(n=4912)$ & 1.00 & - & - \\
\hline & Degree I $(n=31)$ & 6.52 & $2.01-16.90$ & $<0.001$ \\
\hline & Degree II and III (n = 33) & 8.90 & $3.058-20.463$ & $<0.001$ \\
\hline \multirow[t]{3}{*}{ Probing pocket depth } & $<=3 \mathrm{~mm}(\mathrm{n}=981)$ & 1.00 & - & - \\
\hline & $4-6 m m(n=202)$ & 2.01 & $1.28-3.11$ & 0.002 \\
\hline & $7+m m(n=17)$ & 4.18 & $1.19-12.51$ & 0.020 \\
\hline \multirow[t]{3}{*}{ Attachment loss } & No loss $(n=1063)$ & 1.00 & - & - \\
\hline & $1-4$ mm $(n=78)$ & 1.01 & $0.42-2.13$ & 1.000 \\
\hline & $5+\operatorname{mm}(n=59)$ & 1.99 & $0.92-3.97$ & 0.090 \\
\hline \multirow[t]{4}{*}{ Furcation involvement } & No $(n=374)$ & 1.00 & - & - \\
\hline & Degree I $(n=11)$ & 3.06 & $0.70-11.61$ & 0.185 \\
\hline & Degree II $(n=8)$ & 1.96 & $0.23-9.67$ & 0.862 \\
\hline & Degree III (n = 7) & 3.96 & $0.66-21.00$ & 0.177 \\
\hline \multirow[t]{7}{*}{ Coronal status } & Intact $(\mathrm{n}=3951)$ & 1.00 & - & - \\
\hline & Caries $(n=595)$ & 51.24 & $25.69-116.2$ & $<0.001$ \\
\hline & $\begin{array}{l}\text { Intra coronal restoration }(\mathrm{n}= \\
194)\end{array}$ & 18.84 & $6.233-55.579$ & $<0.001$ \\
\hline & Extra coronal restoration $(n=61)$ & 57.11 & $17.173-177.245$ & $<0.001$ \\
\hline & Inadequate restoration $(n=80)$ & 122.84 & $51.389-331.514$ & $<0.001$ \\
\hline & Lost restorations $(n=27)$ & 334.68 & $116.27-1081.62$ & $<0.001$ \\
\hline & Decayed root $(n=68)$ & 753.78 & $331.94-2003.54$ & $<0.001$ \\
\hline \multirow[t]{2}{*}{ Root filling } & Not present $(n=4896)$ & 1.00 & - & - \\
\hline & Present $(n=80)$ & 16.83 & $9.86-28.25$ & $<0.001$ \\
\hline \multirow[t]{2}{*}{ Length of the root filling } & Satisfactory length $(n=47)$ & 1.00 & - & - \\
\hline & Unsatisfactory length $(\mathrm{n}=33)$ & 4.30 & $1.49-13.83$ & 0.005 \\
\hline
\end{tabular}

\section{Discussion}

In Sudan, full dental radiographs are not usually included in routine patients' examination requirements. The aim of this study is detecting risk indicators that could help the general dental practitioner in recognizing individuals with a high risk for AP. It also concentrated on information assumed to be existing to the dentist through patients' history and examination. The present study clearly indicated that age, more than $20 \%$ plaque and more than 4 missing teeth were the best indicators for AP in the individual. AP is frequently a consequence to dental caries, which increases in older individuals. The plaque forms a source of bacteria, which could migrate to the apical tissue through decayed teeth or lateral periodontal ligament space [22,23]. The presence of bacteria and their antigens stimulate the immune system to form a granulation tissue around the apical area. Local immune response eliminates excess numbers of invading organisms. However, in parallel with protective reactions, local activity of immunocompetent cells and their soluble products also contribute to tissue damage, bone resorption and perpetuation of inflammation [24-27]. The missing teeth are more likely to have disease before extraction than present teeth [28]. This study also aimed at identification of teeth with a high risk of having AP. It was revealed that the existence of a root filling extremely increased the risk of AP in the tooth $(\mathrm{OR}=16.83)$. The prevalence of AP in root-filled teeth was $32.5 \%$, which is comparable with other studies that ranged from $25.6 \%$ to $35.6 \%$ [1,2,12,29,30,31,13]. 
It has been proposed previously that, the choice of endodontically treated teeth for radiographic examination is effective in the detection of periapical lesion [32,33,9]. This study results support this findings. Endodontic accomplishment is based on three essential issues: cleaning, shaping and filling. On radiographs, only the last parameter could be estimated.

One of the radiographic measures that can assess the quality of root canal treatment is the length of the root filling $[34,35,5]$. According to that criterion $41.3 \%$ of root filled teeth in this study are inadequately filled root canals.

Despite, the fact that a root filling increases the risk of AP, this study demonstrates that the quality of the root filling is important in relation to the presence of AP. This is also shown in other studies $[36,10,37,38,5,39,33,40,41]$.

There are numerous clarifications for slow or lack of bone formation after inadequate length/extension of root fillings, but this is mainly associated with infection in the apical part of the root canal. Over extension of the root filling may encourage a foreign body reaction at the periapical region that may not be related to the existence or absence of infectious agents or other irritants in the root canal. Over instrumentation often precede overfilling, which may push pulp remnants and microorganisms beyond the apex.

There was no statistical association between AP and smoking or diabetes mellitus; this could be due to small sample size ( 8 smokers and 6 diabetic patients). The evaluation of socioeconomic status was not included in this study. The dental care at dental schools is far less expensive in Sudan when compared to dental care at private clinics. Moreover, all the patients in the study are of middle socioeconomic status and most of them (98.5\%) visit the dentist irregularly. Besides that, many previous studies reported that, the socioeconomic level has no effect on the periapical status of the individuals $[11,42,43,9]$.

\section{Conclusion}

The following conclusions were drawn: The main risk indicators of having AP in the individual were the high plaque percentage, root fillings, the existence of numerous caries lesions and the quality of the dental treatment. The probability of AP was extremely significant after root canal treatment and was closely associated with the quality of the root canal filling.

\section{Abbreviations \\ AP: Apical periodontitis \\ RF: Root-Filled}

\section{Compliance with ethical standards}

\section{Acknowledgments}

To all patients who participated in this study.

\section{Disclosure of conflict of interest}

All the authors declare no conflict of interest.

\section{Statement of ethical approval}

The research protocol was approved by the ethical committee of the dental faculty; University of Khartoum.

\section{Statement of informed consent}

Written Informed consent was obtained from all individual participants included in the study.

\section{References}

[1] Boucher Y, Matossian L, Rilliard F, Machtou P. Radiographic evaluation of the prevalence and technical quality of root canal treatment in a French subpopulation. Int Endod J. 2002; 35: 229-38. 
[2] Buckley M, Spangberg LS. The prevalence and technical quality of endodontic treatment in an American subpopulation. Oral Surg Oral Med Oral Pathol Oral Radiol Endod. 1995; 79: 92-100.

[3] Dugas NN, Lawrence HP, Teplitsky PE, Pharoah MJ, Friedman S. Periapical health and treatment quality assessment of root-filled teeth in two Canadian populations. Int Endod J. 2003; 36: 181-92.

[4] Figdor D. Apical periodontitis: A very prevalent problem. Oral Surg Oral Med Oral Pathol Oral Radiol Endod. 2002; 94: 651-2.

[5] Kabak Y, Abbott PV. Prevalence of apical periodontitis and the quality of endodontic treatment in an adult Belarusian population. Int Endod J. 2005; 38: 238-45.

[6] Marcus T, Yan. The management of periapical lesions in endodontically treated teeth. Aust Endod J. 2006; 32: 215.

[7] Tsuneishi M, Yamamoto T, Yamanaka R, Tamaki N. Radiographic evaluation of periapical status and prevalence of endodontic treatment in an adult Japanese population. Oral Surg Oral Med Oral Pathol Oral Rdiol Endod. 2005; 100: 631-5.

[8] Paul V, Abbott. Classification, diagnosis and clinical manifestations of apical periodontitis. Endod Topics. 2004; 8: 36-54.

[9] Kirkevang LL, Wenzel A. Risk indicators for apical periodontitis. Community Dent Oral Epidemiol. 2003; 31: 5967.

[10] Eriksen HM, Bjertness E. Prevalence of apical periodontitis and results of endodontic treatment in middle-aged adults in Norway. Endod Dent Traumatol. 1991; 7: 1-4.

[11] Frisk F, Hugoson A, Hakeberg M. Technical quality of root fillings and periapical status in root filled teeth in Jonkoping, Sweden. Int Endod J. 2008; 41: 958-68.

[12] Imfeld TN. Prevalence and quality of endodontic treatment in an elderly urban population of Switzerland. J Endod. 1991; 17: 604-7.

[13] Tavares PB, Bonte E, Boukpessi T, Siqueira JF, Jr., Lasfargues JJ. Prevalence of apical periodontitis in root canaltreated teeth from an urban French population: influence of the quality of root canal fillings and coronal restorations. J Endod. 2009; 35: 810-3.

[14] Georgopoulou MK, Spanaki-Voreadi AP, Pantazis N, Kontakiotis EG, Morfis AS. Periapical status and quality of root canal fillings and coronal restorations in a Greek population. Quintessence Int. 2008; 39: e85-92.

[15] Ray HA, Trope M. Periapical status of endodontically treated teeth in relation to the technical quality of the root filling and the coronal restoration. Int Endod J. 1995; 28: 12-8.

[16] Eriksen HM, Berset GP, Hansen BF, Bjertness E. Changes in endodontic status 1973-1993 among 35-year-olds in Oslo, Norway. Int Endod J. 1995; 28: 129-32.

[17] Ainamo A, Soikkonen K, Wolf J et al. Dental radiographic findings in the elderly in Helsinki, Finland. Acta Odontol Scand. 1994; 52: 243-9.

[18] Catanzaro O, Dziubecki D, Lauria LC, Ceron CM, Rodriguez RR. Diabetes and its effects on dental pulp. J Oral Sci. 2006; 48: 195-9.

[19] Ilguy M, Ilguy D, Bayirli G. Dental lesions in adult diabetic patients. N Y State Dent J. 2007; 73: 58-60.

[20] Segura-Egea JJ, Jimenez-Pinzon A, Rios-Santos JV, Velasco-Ortega E, Cisneros- Cabello R, Poyato-Ferrera MM. High prevalence of apical periodontitis amongst smokers in a sample of Spanish adults. Int Endod J. 2008; 41, 310-6.

[21] Skudutyte-Rysstad R, Eriksen HM. Endodontic status amongst 35-year-old Oslo citizens and changes over a 30year period. Int Endod J. 2006; 39: 637-42.

[22] Rocas IN, Siqueira JF, Jr. Root canal microbiota of teeth with chronic apical periodontitis. J Clin Microbiol. 2008; 46: 3599-606.

[23] Rupf S, Kannengiesser S, Merte K, Pfister W, Sigusch B, Eschrich K. Comparison of profiles of key periodontal pathogens in periodontium and endodontium. Endod Dent Traumatol. 2000; 16: 269-75.

[24] Gonzalez-Moles MA, Gonzalez NM. Bacterial infections of pulp and periodontal origin. Med Oral Patol Oral Cir Bucal. 2004; 9 Suppl: 34-6; 32-4. 
[25] Marton IJ, Kiss C. Protective and destructive immune reactions in apical periodontitis. Oral Microbiol Immunol. 2000; 15: 139-50.

[26] Rocas IN, Siqueira JF, Jr. Prevalence of new candidate pathogens Prevotella baroniae, Prevotella multisaccharivorax and as-yet-uncultivated Bacteroidetes clone X083 in primary endodontic infections. J Endod. 2009; 35: 1359-62.

[27] Silva TA, Garlet GP, Fukada SY, Silva JS, Cunha FQ. Chemokines in oral inflammatory diseases: apical periodontitis and periodontal disease. J Dent Res. 2007; 86: 306-19.

[28] Lawrence HP, Beck JD, Hunt RJ, Koch GG. Adjustment of the M-component of the DMFS index for prevalence studies of older adults. Community Dent Oral Epidemiol. 1996; 24: 322-31.

[29] Lupi-Pegurier L, Bertrand MF, Muller-Bolla M, Rocca JP, Bolla M. Periapical status, prevalence and quality of endodontic treatment in an adult French population. Int Endod J. 2002; 35: 690-7.

[30] Sidaravicius B, Aleksejuniene J, Eriksen HM. Endodontic treatment and prevalence of apical periodontitis in an adult population of Vilnius, Lithuania. Endod Dent Traumatol. 1999; 15: 210-5.

[31] Soikkonen KT. Endodontically treated teeth and periapical findings in the elderly. Int Endod J. 1995 ; 28 : 200-3.

[32] Estrela C, Leles CR, Hollanda AC, Moura MS, Pecora JD. Prevalence and risk factors of apical periodontitis in endodontically treated teeth in a selected population of Brazilian adults. Braz Dent J. 2008; 19: 34-9.

[33] Kirkevang LL, Vaeth M, Wenzel A. Tooth-specific risk indicators for apical periodontitis Oral Surg Oral Med Oral Pathol Oral Radiol Endod. 2004; 97: 739-44.

[34] De Moor RJ, Hommez GM, De Boever JG, Delme KI, Martens GE. Periapical health related to the quality of root canal treatment in a Belgian population. Int Endod J. 2000; 33: 113-20.

[35] Genc Y, Gulsahi K, Gulsahi A et al. Assessment of possible risk indicators for apical periodontitis in root-filled teeth in an adult Turkish population. Oral Surg Oral Med Oral Pathol Oral Radiol Endod. 2008; 106: e72-7.

[36] Chen CY, Hasselgren G, Serman N, Elkind MS, Desvarieux M, Engebretson SP. Prevalence and quality of endodontic treatment in the Northern Manhattan elderly J Endod. 2007; 33: 230-4.

[37] Hommez GM, Coppens CR, De Moor RJ. Periapical health related to the quality of coronal restorations and root fillings. Int Endod J. 2002; 35: 680-9.

[38] Iqbal MK, Johansson AA, Akeel RF, Bergenholtz A, Omar R. A retrospective analysis of factors associated with the periapical status of restored, endodontically treated teeth. Int J Prosthodont. 2003; 16: 31-8.

[39] Kirkevang LL, Vaeth M, Horsted-Bindslev P, Wenzel A. Longitudinal study of periapical and endodontic status in a Danish population. Int Endod J. 2006; 39: 100-7.

[40] Segura-Egea JJ, Jimenez-Pinzon A, Poyato-Ferrera M, Velasco-Ortega E, Rios-Santos JV. Periapical status and quality of root fillings and coronal restorations in an adult Spanish population. Int Endod J. 2004; 37: 525-30.

[41] Siqueira JF, Jr., Rocas IN, Alves FR, Campos LC. Periradicular status related to the quality of coronal restorations and root canal fillings in a Brazilian population. Oral Surg Oral Med Oral Pathol Oral Radiol Endod. 2005; 100: 369-74.

[42] Frisk F, Hakeberg M. Socio-economic risk indicators for apical periodontitis. Acta Odontol Scand. 2006; 64: 1238.

[43] Kirkevang LL, Bahrami G, Wenzel A. Risk factors for developing apical periodontitis in a general population. Int Endod J. 2007; 40: 290-9. 